Review

\title{
Fascial or Muscle Stretching? A Narrative Review
}

\author{
Carla Stecco $^{1}\left(\mathbb{D}\right.$, Carmelo Pirri ${ }^{1, *(\mathbb{D}}$, Caterina Fede ${ }^{1(\mathbb{D})}$, Can A. Yucesoy ${ }^{2}$, Raffaele De Caro ${ }^{1, *(\mathbb{D})}$ and \\ Antonio Stecco ${ }^{3}$
}

check for updates

Citation: Stecco, C.; Pirri, C.; Fede, C.; Yucesoy, C.A.; De Caro, R.; Stecco, A. Fascial or Muscle Stretching? A Narrative Review. Appl. Sci. 2021, 11, 307. https://doi.org/10.3390/app11 010307

Received: 17 November 2020 Accepted: 25 December 2020 Published: 30 December 2020

Publisher's Note: MDPI stays neutral with regard to jurisdictional clai$\mathrm{ms}$ in published maps and institutional affiliations.

Copyright: (C) 2020 by the authors. Licensee MDPI, Basel, Switzerland. This article is an open access article distributed under the terms and conditions of the Creative Commons Attribution (CC BY) license (https:// creativecommons.org/licenses/by/ $4.0 /)$.
1 Department of Neurosciences, Institute of Human Anatomy, University of Padua, 35121 Padua, Italy; carla.stecco@unipd.it (C.S.); caterina.fede@unipd.it (C.F.)

2 Institute of Biomedical Engineering, Bogazici University, 34684 Istanbul, Turkey; can.yucesoy@boun.edu.tr

3 RUSK Rehabilitation, New York University School of Medicine, New York, NY 10016, USA;

Antonio.Stecco@nyulangone.org

* Correspondence: carmelop87@hotmail.it (C.P.); rdecaro@unipd.it (R.D.C.)

\begin{abstract}
Stretching exercises are integral part of the rehabilitation and sport. Despite this, the mechanism behind its proposed effect remains ambiguous. It is assumed that flexibility increases, e.g., action on muscle and tendon, respectively, but this is not always present in the stretching protocol of the exercises used. Recently, the fasciae have increased popularity and seems that they can have a role to define the flexibility and the perception of the limitation of the maximal range of motion (ROM). Deep fascia is also considered a key element to transmit load in parallel bypassing the joints, transmitting around $30 \%$ of the force generated during a muscular contraction. So, it seems impossible dividing the action of the muscles from the fasciae, but they have to be considered as a "myofascial unit". The purpose of this manuscript is to evaluate the mechanical behavior of muscles, tendons, and fasciae to better understand how they can interact during passive stretching. Stress-strain values of muscle, tendon and fascia demonstrate that during passive stretching, the fascia is the first tissue that limit the elongation, suggesting that fascial tissue is probably the major target of static stretching. A better understanding of myofascial force transmission, and the study of the biomechanical behavior of fasciae, with also the thixotropic effect, can help to design a correct plan of stretching.
\end{abstract}

Keywords: fascia; biomechanics; exercise; injury and prevention; musculoskeletal; stretching

\section{Introduction}

Stretching exercises are widely used in rehabilitation and sports. However, even though stretching has been demonstrated to cause instantaneous and long-lasting changes in maximal joint range of motion (ROM) (commonly referred as flexibility), its mechanism has not clearly been demonstrated yet [1]. For example, various authors have investigated the effects of static stretching training program on active tendon stiffness, but after six weeks of training they did not show any influence on active tendon stiffness [2], suggesting that also other mechanisms need to be considered to explain the effects of stretching. Moreover, Nakamura et al. [3] demonstrated that static stretching might be effective for decreasing muscle stiffness of the medial and lateral gastrocnemius. Another doubt about stretching is "the lack of a relationship between electromyography (EMG) response and viscoelastic stress relaxation during a static stretch [4], and the incongruity between the observed EMG response and the most effective stretching technique" [5]. Magnusson et al. [6] showed, in response to passive static stretch in spinal cord injury subjects, up to $38 \%$ decrease in passive torque, despite the absence of any measurable EMG activity, proving the existence of a viscoelastic stress relaxation response during a static stretch.

It was reported that stretching efficacy was not limited only to the joint moved. Chaouachi et al. [7] showed that unilateral stretching, targeting only one lower limb, also increased the ROM of the contralateral limb. More recently, Behm et al. [8], showed how an acute bout of stretching of the lower limbs, increased the maximal ROM of the 
distant upper limbs and vice versa. Wilke et al. [9] demonstrated that an acute bout of stretching of the lower limb muscles, induced an increase in the maximal ROM of the cervical spine. To explain these data, Wilke et al. [9] suggest that we need to take in consideration the possible role of fasciae to connect the various muscles along specific lines. Cruz-Montecinos et al. [10] reported "a significant correlation between the pelvic anteversion (forward tilting), in a long sitting position (knees fully extended), and the displacement of the deep fasciae of the gastrocnemius medialis, supporting the concept of myofascial tissue connectivity. Thus, fasciae could sustain notable stress levels during stretching maneuvers that involve polyarticular motion such as the slump position or straight-leg raising" [11]. Together, these findings strongly suggest that maximal ROM may be limited by non-muscular structures such as fascia tissue. Deep fascia is a continuous layer from the trunk across the upper and lower limbs (Figure 1) and it is considered the key element to transmit load in parallel bypassing the articulation. Besides, it gives insertion and origin to muscle fibers with a percentage estimated around 30\% [12]. Moreover, fascia is an uninterrupted viscoelastic tissue made by layers of dense connective tissue (collagen type I and III) interfaced by loose connective tissue that present a typical viscoelastic property [13]. The loose connective tissue is composed by adipose cell, glycosaminoglycans (GAG) and hyaluronan (HA) [14]. The deep fasciae could be distinguished in two major groups: the epimysial fasciae and the aponeurotic fasciae [15] (Figure 1). The former comprises all the connective tissues that surround and interpenetrate the muscles and the tendon, and are hardly adherent to them, such as epimysium, perimysium, and endomysium. These fasciae form a functional unit with the surrounding muscular fibers, and they are responsible of the epimuscular myofascial force transmission [16]. The latter are fibrous connective tissue layers that cover the muscles and connect different segments at a distance. The most important aponeurotic fasciae are: fascia lata, brachial, crural, and antebrachial fasciae, thoracolumbar fascia and rectus abdominal sheath. These fasciae are free to glide with respect to the underlying muscles owing to a thin layer of loose connective tissue, and present only few and very specific connections with the underlying musculature, referred to as myofascial expansions [17]. In such perspective it is possible to study in a separate way, the mechanical proprieties of the aponeurotic fasciae with respect to those of the underlying muscles. Besides, in the daily life, the aponeurotic fasciae always collaborate with muscles [18]. Indeed, when muscles contract to cause movement, they simultaneously stretch the related myofascial expansions, transmitting part of the muscular force to the aponeurotic fascia in a very specific area. These myofascial expansions have the role to reduce stress concentration by providing an increased area of force transmission, but also to activate specific patterns of nerve elements inside fasciae, and so playing a fundamental role in proprioception. Consequently, the muscle-fascia relationship could be highlighted in two different levels: a microscopic level, where each muscle fiber interacts with the extracellular matrix and it is strongly dependent of its viscoelasticity, and a macroscopic level, where each muscle is enveloped by an aponeurotic fascia. Many authors $[19,20]$ refer to myofascial force transmission, as force generated, to be exerted through the full perimeter surface of the muscle fibers onto the extracellular matrix and from there to extramuscular connective tissue $[20,21]$. This connective tissue organization allows transmission of force from muscle to surrounding structures including synergistic muscles within a compartment as well as antagonistic muscles within other compartments [16]. Yucesoy et al. [16] have shown "that adjacent synergistic muscles cannot be seen as independent functional units due to substantial amounts of muscle force transmitted from the direct collagenous connections between muscles via shared epimysia, i.e., intermuscular myofascial force transmission [22] and the extracellular matrix of a muscle to surrounding non-muscular elements of a compartment and bone i.e., extramuscular myofascial force transmission" [23]. Inter- and extramuscular myofascial force transmission combined is referred to as epimuscular myofascial force transmission [24]. Such force transmission has been shown to occur in human e.g., in cerebral palsy patients as shown by intraoperative experiments [25]. Different authors have proven, through multiple dissections, the anatom- 
ical relation between gluteus maximus and fascia lata [26], the myofascial continuity in the anterior region of the upper limb, and the tendinous muscular insertions onto the deep fascia of the upper limb [27].

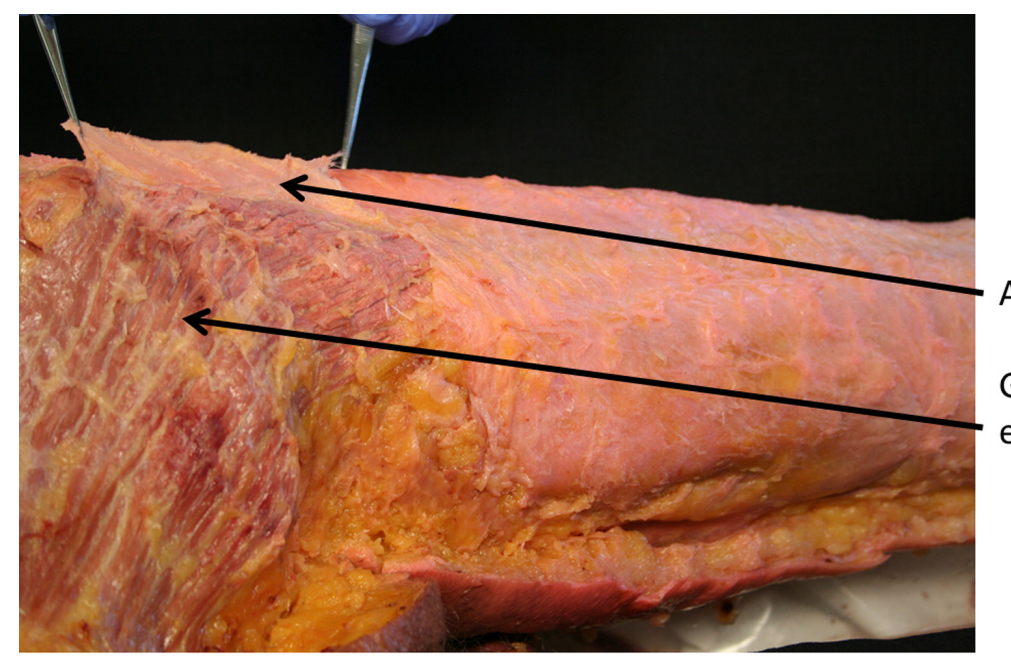

\section{Aponeurotic fascia (fascia lata)}

Gluteus maximus with tis

epimysial fascia

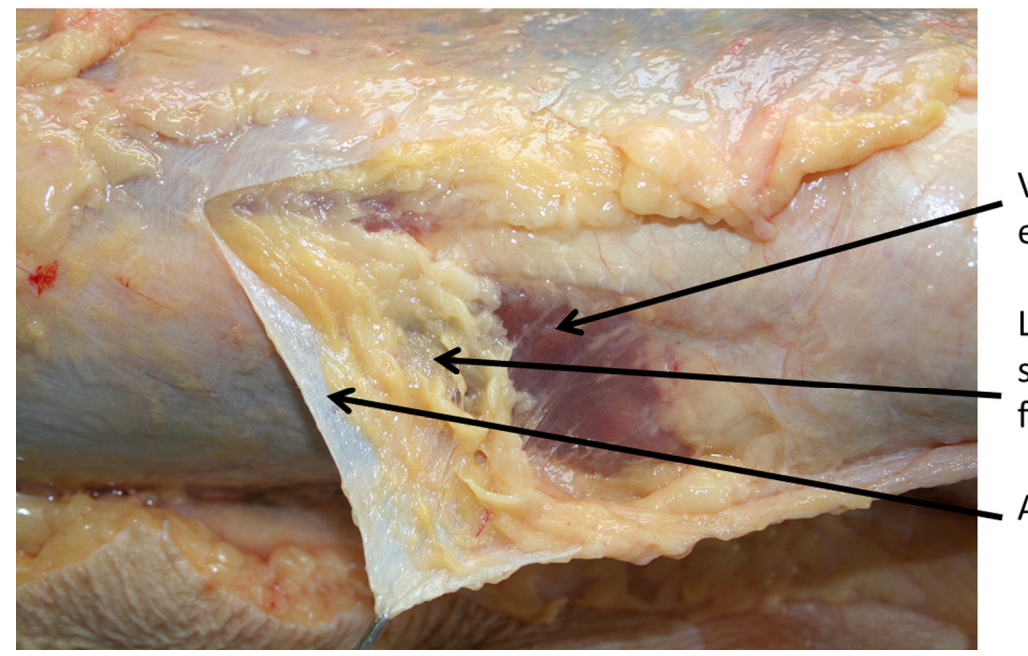

Vastus lateralis muscle with its epimysial fascia

Loose connective tissue and fat separating the aponeurotic fascia from muscle Aponeurotic fascia (fascia lata)

Figure 1. Epimysial and aponeurotic fasciae. In the first figure it is evident the fascia lata (aponeurotic fascia) easily separable from the gluteus maximum muscle. Note the adhesion of the gluteal fascia with its own muscle typical of the epimysial deep fascia. In the bottom figure, the fascia lata is separable from the vastus lateralis muscle thanks to loose connective tissue rich also in fat. In such way the fascia lata is mostly independent from the underline muscle.

At a microscopic level the trans-sarcolemmal molecules connect the cytoskeleton to laminin, which is connected to the basal lamina [28], which in turn is connected to the endomysium [29], that forms a 3D structure of tunnels within which the muscle fibers are operating. Moreover, Passerieux et al. [30] have identified "specialized connections between muscle fibers with their basal lamina as well as endomysium and the perimysium. These pathways have been shown to transmit muscle force within single isolated muscle fibers, within isolated fascicles [31] within a dissected muscle in situ" [19]. Due to such intramuscular myofascial force transmission [20] muscle fibers cannot be seen as independent functional units, but it could be better described as myofascial unit [32].

Nordez et al. [33] have hypothesized that some mechanical adaptations after chronic stretching interventions might occur also at fascia level. However, it is necessary to consider that the resistance to stretch is different among tendon, muscle and fascia owing to differences in tissue mechanical properties, but, at the same time, their integrative action is crucial. 
Moreover, thixotropy is another important property that can change the viscoelastic properties of the extracellular matrix in tendon, fascia, and muscle [34].

The aim of this manuscript is to review the differences and similarities between muscle, tendon, and aponeurotic fascia in the mechanical behaviors and thixotropic effect in order to better understand their integrative action when stretch is applied.

\section{Materials and Methods}

This article is not intended to be a comprehensive review but, instead, it addresses the biomechanical characteristic of the deep fascia tissue in comparison with muscles and tendons, in order to better understand the mechanisms of static stretching. PubMed, Scopus and Google Scholar database was searched for experimental studies. This review integrated studies that examined stress/strain curve, stress/relaxation curve, thixotropic effect/thixotropy on muscle, tendon, and fascia. No restriction in time was applied. The research was performed using the following keywords in combination: (stress/strain curve OR stress/relaxation curve OR thixotropic effect/thixotropy) AND (muscle OR tendon OR fascia).

The methodological design of the review included a group of criteria that had to be adhered to select only relevant studies. Studies were included in the review if they contained research questions regarding the keywords and used healthy animals and humans, both in vivo and in vitro. We excluded pathological conditions. This search was extended utilizing the bibliography within the recruited texts. Relevant secondary references, as books, were also captured. The search was limited to studies published in English, in which fascia, tendon and muscles were considered as a target for stretching.

\section{Results}

Overall, a limited literature was detected on fascia, while muscle and tendon appeared to be a better-studied tissue. Regarding the keywords the articles were captured for every topic about biomechanical behavior and thixotropic effect. Biomechanical data may not be comprehensive in order to have a clear understanding of muscle role in the biomechanics of human body, but want to underline the differences among muscle, tendon and fascia highlighting the possible role of fascia in the stretching.

\subsection{Stress/Strain Curve}

The stress/strain curve (stress represents the applied force per area, while strain expresses the percentage of elongation beyond resting length) evaluates the mechanical behavior of soft tissues. In stress-relaxation test, a predefined tensile strain is applied, and corresponding stress is followed as a function of time. All biphasic and viscoelastic soft tissues exhibit first the relaxation phase and then the entire load is carried by the solid matrix of a tissue. Consequently, in all the stress/strain curves of musculoskeletal soft tissue we can recognize, at the beginning phase of tension test, the so called the toe region. In this region, the relation between stress and strain is nonlinear and the slope is increasing with increased loading. The reason for the increasing slope is the straightening of the wavy-like collagen fibrils. After the collagen fibrils are completely straightened, the elastic region begins. In this region, the stress and strain are linearly related and the slope of the curve is called the tissue Young's modulus. In the elastic range, all changes of a tissue are still reversible, i.e., if the stress is removed tissue returns to the original strain. It should be also noted that in human musculoskeletal soft tissues, the loading rate affects the slope of the elastic range, i.e., higher loading rate results to steeper slope and higher Young's modulus value. When the stress is further increased from the elastic region, the slope of the curve changes and the plastic region begins. This is called the yield point. After the yield point tissue begins to experience destructive changes, e.g., microfractures in the collagen fibril network. In the plastic region irreversible changes have occurred in a tissue and it does not return to the original strain although the stress would be completely removed. The stress corresponding to such yield point is one characteristic parameter reported for 
soft tissues under destructive testing. After the plastic region, the sudden failure of the tissue occurs and stress vanishes. The stress corresponding to such breakdown is called the failure point, which is another characteristic parameter reported [35].

In the literature stress-strain curves of many soft tissues have been reported. The tendon and the muscle are the most studied tissues, whilst for the aponeurotic fasciae there is only limited data for the plantar fascia [36] and for the crural fascia [37,38]. The stress-strain curve of the fascia is non-linear, due to the uncrimping of collagen fibers and elasticity generate by elastin fibers, with the initial portion of stress-strain curve showing a high deformation/low force characteristic. For each increasing increment of applied strain, the fascia answers with a corresponding increase of stress. When all collagen fibers are fully uncrimped and oriented in the direction of the load, the amount of stress is totally governed by the cumulative behavior of tensed collagen fibers. In the experiment of Stecco et al. [37], the crural fascia showed a peak strain of about $27 \%$ for the specimens of the anterior compartment, and $27.5 \%$ for the specimens of the posterior compartment. Besides, it presented also a strong anisotropy due to the specific collagen fibers orientation, being stiffer along the proximal-distal than along medial-lateral direction. In the study of Pavan et al. [36], the peak strain was about $12 \%$ for the plantar fascia.

The mechanical behavior of muscle tissue has been studied in different ways because muscle has a hierarchical structure. This is comprised of micro to macro components of different lengths and structural scales, e.g., a sarcomere, myofibril, fiber, fascicle, whole muscle, and muscle-tendon unit [39]. For example, Meyers et al. [40] studied almost intact muscletendon units in vivo; thus, their data take in consideration also the stiff membranous materials such as the epimysium and aponeurosis. On the contrary, in the experiments of Tamura et al. [41], only muscle fiber bundles were tested, so they included endomysium and perimysium but not epimysium and aponeurosis. Therefore, the difference in the reported mechanical failure stresses may be partly attributable to the additional strength provided by the extracellular matrix in the Meyers' study. Tamura et al. [41] have shown "that the ultimate tensile strain of muscle fiber bundles was almost constant at approximately $54 \%$ regardless of the magnitude of the externally applied loading rate". Schleifenbaum et al. [42] identify the failure region of the stress-strain curve in the muscle around $75 \%$ of elongation in direction of the muscle fiber. This value has a great variability in relation to muscle fibers' orientation and presence or not of the epimysium, consequently depending on the type of the muscle.

Besides, according to Tamura et al. [41], the stress-relaxation rate significantly depends on the magnitude of the applied stretch. Meyers et al. [40], investigating the effect of the strain rate on the tibialis anterior muscle of New Zealand white rabbits in vivo, demonstrated that the stress-strain response of passive skeletal muscle is quite sensitive to the stretching velocity over a range of strain rates $(1-25 s-1)$. Moreover, the failure stress was in the range of 0.5-1.1 MPa, which was higher than the tensile strength reported by Tamura et al. [43].

In the tendon stress-strain curve, the linear region begins at approximately $2 \%$ of the strain for most tendons. In this region tendon elongation results from stretching prealigned collagen fibers, and hence the stiffness is indicative of the collagen fiber stiffness (material stiffness). Microscopic tearing can occur if the tendon is stretched beyond $4 \%$ of its original length [44]. The strain patterns in some tendons are not uniform along their lengths. They may exhibit stress-shielded areas and even areas subjected to compressive loading, especially at the enthesis. However, the force transmission between the external and internal parts of the tendon for the majority of human muscles remains unknown. The tendon has a stress-strain curve similar to fascia with a faster increase of the stress in response to increasing of the strain. Tendon is less adaptable than fascia, but being in series with the muscle, it can compensate its stiffness with a lengthening of the muscle (Figure 2) $[45,46]$. 


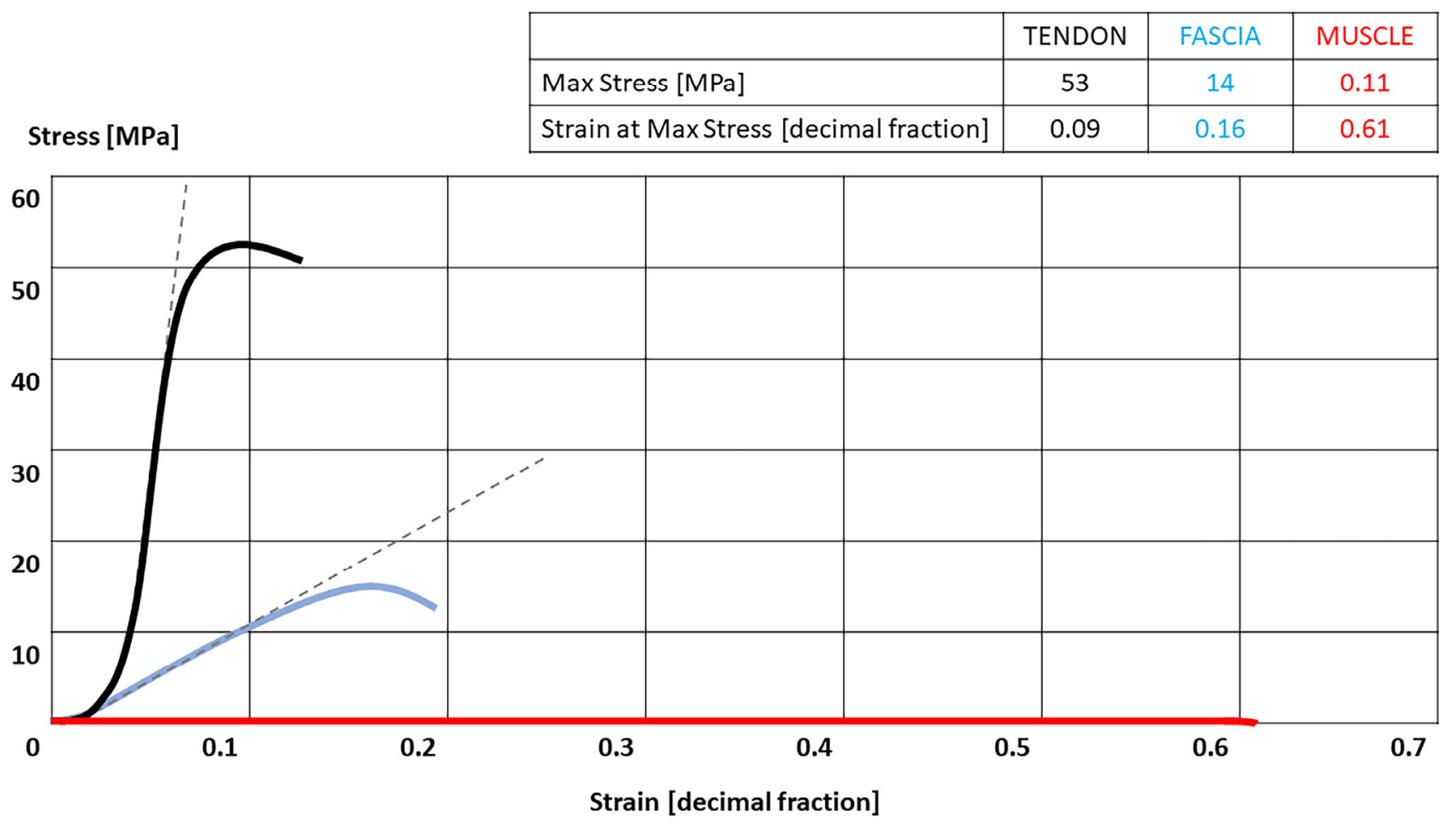

Figure 2. Stress-strain curves of the tendon, fascia [45] and muscle [46]. Tendon = black; fascia = blue; Muscles = red. Table present the highest Stress that each tissue can tolerate with their correspondence strain.

The hysteresis area represents the energy loss in a loading-unloading deformation cycle, mainly due to converting mechanical work into heat. Hysteresis is often quantified as the ratio of the hysteresis loop divided by the area under the loading curve. The ratio represents the percentage of the mechanical energy loss in the loading-unloading cycle. The hysteresis is manifested as the hysteresis loop. No clear literature was found regard the results for the muscle and hysteresis curves of the muscle fibers are unspecific. They not really deal with what happens inside the muscle. For tendon, the information regarding the effects of the strain rate on tendon hysteresis remains limited [47-49]. When a tendon is forcibly stretched, the area beneath the force-deformation curve represents the mechanical work done to extend the tendon (work $=\int \mathrm{F} \times \mathrm{dE}$, where $\mathrm{F}$ is force acting in the direction of tendon extension E). For the same level of tendon extension, the force during loading is larger than the force during unloading. In the fascia, the unloading curve will not follow the loading curve. The area between the two curves represents the amount of energy that is dissipated or lost as heat during loading (hysteresis area) due to viscous phenomena. The area under the unloading curve represents the returned energy [36].

\subsection{Stress/Relaxation Curve}

Stress/relaxation curve characterizes a key viscoelastic property i.e., a time-dependent decrease in stress under constant strain. Magnusson et al. [6] have shown that the muscletendon unit, when stretched to a constant length analogous the static stretching technique, declines in tension over time showing a viscoelastic response. Viscoelastic stress relaxation of the muscle and tendon have been demonstrated in vitro [2] and in vivo in human skeletal muscle $[7,33,36]$ have shown such mechanical response in deep fascia after static stretching. However, as a notable issue, the stress relaxation curve was the same in all the three subsequent relaxation tests with constant tensile nominal strain of increasing magnitude $(4,6$, and $8 \%)$, indeed the stress was reduced of a percentage of $35-40$ in a time interval of $120 \mathrm{~s}$, without dependency on the level of strain applied. In contrast, the rate of stress relaxation in tendon has been shown to increase with increasing strain [50]. The tendon displays more viscoelastic behavior at higher strains and more elastic behavior at lower 
strains. Similar to data on whole muscle and collagen [2], the non-linear stress relaxation has an initial steep component with a subsequent more gradual relaxation component.

\subsection{Thixotropic Effect}

Thixotropy is a property of a substance to decrease its viscosity when it is shaken or stirred and then solidify when left to stand [34]. It was demonstrated that muscle possesses thixotropic properties due to formation of "weak" actin-myosin cross-bridges in resting muscle [51]. As the muscle is elongated, decreasing overlap of actin and myosin chains provides relatively few binding sites. The greatest number of actin-myosin binding sites are available when the muscle fibers are at intermediate length [52].

In the tendon, many factors can change the viscoelastic proprieties of the extracellular matrix, and consequently tendon plays an important role in the force transmission and tissue structure maintenance. For example, with aging, glycation contributes to additional cross-linking, which modifies tissue stiffness [53].

The thixotropy is present also in the fasciae, related to one of the major constituents, i.e., the hyaluronan (HA) [17]. The viscosity coefficient of HA is not constant, and this fluid is not linearly viscous, but its viscosity is reduced under any loading condition, whilst the rest condition allows HA to return to a more viscous state [54]. Chytil et al. [55] demonstrated that, at lower shear stress levels, chains of high molecular size HA (106-107 Da) are efficient in re-associating in their previous superstructure after the load has been removed. If the HA assumes more packed conformation, it increases the density of the loose connective tissue inside the fasciae, and consequently the behavior of the whole deep fascia could be compromised [16]. Additionally, the concentration of HA can change the viscosity of the fascial loose connective tissue, indeed in high concentrations HA chains entangle, contributing to create more viscous solution [56,57]. The HA mechanical proprieties also change with temperature. In particular, the three-dimensional superstructure of HA chains progressively breaks down when the temperature is increased to $>40{ }^{\circ} \mathrm{C}$ [58], with a consequent decrease in viscosity. Additionally, alterations of $\mathrm{pH}$ can change the viscosity of HA [59], in particular HA becomes more viscous in acid solution. Juel et al. [60] demonstrated that after strenuous exercises in the muscle compartment, the $\mathrm{pH}$ can reach a value of 6.60 due to the lactate accumulation. That means an increase of approximately $20 \%$ in HA viscosity, with a consequent sensation of stiffness.

\section{Discussion}

This narrative review highlighted the different mechanical behaviors of the muscle, tendon and fascia and confirms the idea that the structural conformation of the fasciae has to interact with muscular contraction $[16,60]$. Regarding both stress/strain and stress/relaxation curves, the deep fasciae better match the range of excursion that static stretching exercises generate. Indeed, the tissue lengthening imposed in a classical passive stretching of the posterior part of the leg (fingertip-to toes test), has a mean value of $20 \mathrm{~cm}$ $(\mathrm{SD} \pm 22)($ range 0-49 $\mathrm{cm}$ ) [61]. Recalling that tendon reaches non-physiological stretch at approximately $4 \%$, when micro tears will begin [43], while beyond $75 \%$ for muscle [41], it is plausible that the strain imposed in such passive stretching is beyond what tendon can tolerate and way lower of muscle stress/strain curve peak. Considering 90 and $84 \mathrm{~cm}$ as mean value of leg length respectively for men and female [62], the deep fascia is able to resist up to $27 \%$ of its elongation, corresponding to approximately $20 \mathrm{~cm}$ maximal extension of aponeurotic fasciae (Figure 2). This value better represents the stretching excursion range typically performed during the fingertip-to-toes test.

All the three considered tissues present viscoelastic proprieties, that means that they decline in tension over time when stretched to a new constant length, analogous to the static stretching technique. In concert with that, among the tissues addressed, aponeurotic and epimysial fasciae presents the highest viscoelastic deformation due to the high concentration of GAG and hyaluronan. This physical characteristic explains the interesting results obtained during stress-relaxation curve, as well the thixotropic phenomena. 
This property can also explain why immobility reduces fascial gliding and, consequently, range of motion, as could be the ankles-feet stiffness during the first few steps out of bed in the morning [63,64]. Herda et al. [65] reported that passive resistive torque and passive stiffness decreased following 2 min of dynamic stretching, indicating modifications in the viscoelastic properties of the muscular-tendon unit (MTU). Similarly, Nordez et al. [66] have reported "that viscosity plays a major role in passive stiffness changes during cyclic stretching protocols and proposed it may be likely due to the rearrangement/slipping of collagen fibers in the short term and maybe a plastic effect in the long term (years) due to a remodeling of the single collagen fibers". It has been proposed that an increase in temperature may decrease the viscous resistance of muscles [67] and by consequence reduce passive resistive torque and MTU stiffness [68].

Together, these results suggest that static stretching can induce an increase in the "overall stretch tolerance", not limited to the muscles and tendons involved, but involving also the fasciae of the anatomic region. Besides, considering the stress-strain curves of the various soft tissues, probably the fasciae could be considered the limiting factor (Figure 3) [69], and consequently we need to take care of all the elements that can modify the fascial viscoelastic properties to improve the stretching efficacy.

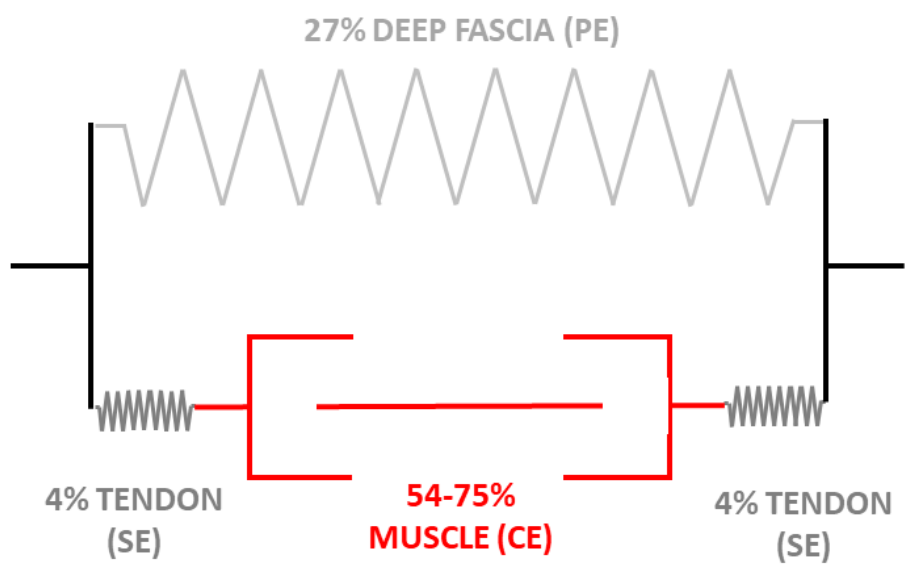

Figure 3. Schematic description of a finite element model based on the Hill's three-element model (1938) for muscle, fascia, and tendon localize in the inferior limb in anatomical disposition: muscle and tendon are in series, while fascia is in parallel in the leg. During stretching, without muscle contraction, the fascia becomes the first tissue that limits the extension. With muscle contraction, tendon and muscle limit the stretching exercise. CE: Contractile Element; SE: Series Element; PE: Parallel Element. Nerve stiffness or restrictions of e.g., ligaments or skin have not included in this analysis. The plot is based on Morales-Orcajo E. et al. [45], Soderberg, G.L. [46], and Pavan PG et al. [38] publications.

\section{Limits}

This review has not included all the mechanical studies published in old textbooks. Besides, we have considered only the static stretching, also if in accordance with the literature, dynamic stretching appears to be more appropriate than static stretching for performance. However, most of the biomechanical studies on soft tissues report only static results and not dynamic. Moreover, this review considers only the biomechanical effects on the soft tissues, without taking into consideration the effect of stretching on the peripheral and central nervous system.

\section{Conclusions}

With this review we support the role of non-muscular structures, such as fasciae, in flexibility, perception of stretch, and limitation of the maximal ROM. The knowledge of the mechanical properties of the human fasciae could permit a rational explanation of possible response/modification of these tissues to various types of stretching. During 
stretching, the bulk of the mechanical work is done on the aponeurotic fascia that is the first one that is stretched when the muscles are not in isometric contraction. Only secondarily muscle and tendon are involved. Without understanding myofascial force transmission, we will never be able to understand muscular function completely and to design a correct plan of stretching for the patients and healthy people.

Author Contributions: Conceptualization, C.S., A.S.; investigation, C.P. and C.A.Y.; methodology, C.P., C.F. and A.S.; formal analysis, C.A.Y. and C.F.; writing-original draft, C.S., C.P., A.S.; writingreview and editing, C.S., C.P., R.D.C., A.S. All authors have read and agreed to the published version of the manuscript.

Funding: This research received no external funding.

Acknowledgments: The authors thank the Institute of Human Anatomy, University of Padua.

Conflicts of Interest: The authors declare no conflict of interest.

\section{References}

1. Cornelius, W.L.; Ebrahim, K.; Watson, J.; Hill, D.W. The Effects of Cold Application and Modified PNF Stretching Techniques on Hip Joint Flexibility in College Males. Res. Q. Exerc. Sport 1992, 63, 311-314. [CrossRef] [PubMed]

2. Konrad, A.; Tilp, M. Increased range of motion after static stretching is not due to changes in muscle and tendon structures. Clin. Biomech. 2014, 29, 636-642. [CrossRef] [PubMed]

3. Nakamura, M.; Ikezoe, T.; Nishishita, S.; Umehara, J.; Kimura, M.; Ichihashi, N. Acute effects of static stretching on the shear elastic moduli of the medial and lateral gastrocnemius muscles in young and elderly women. Musculoskelet. Sci. Pract. 2017, 32, 98-103. [CrossRef] [PubMed]

4. Magnusson, S.P.; Simonsen, E.B.; Aagaard, P.; Gleim, G.W.; McHugh, M.P.; Kjaer, M. Viscoelastic response to repeated static stretching in human skeletal muscle. Scand. J. Med. Sci. Sport 1995, 5, 342-347. [CrossRef] [PubMed]

5. Osternig, L.R.; Robertson, R.N.; Troxel, R.K.; Hansen, P. Differential responses to proprioceptive neuromuscular facilitation (PNF) stretch techniques. Med. Sci. Sports Exerc. 1990, 22, 106-111. [CrossRef]

6. Magnusson, S.P.; Simonsen, E.B.; Dyhre-Poulsen, P.; Aagaard, P.; Mohr, T.; Kjaer, M. Viscoelastic stress relaxation during static stretch in human skeletal muscle in the absence of EMG activity. Scand. J. Med. Sci. Sports 1996, 6, 323-328. [CrossRef]

7. Chaouachi, A.; Padulo, J.; Kasmi, S.; Ben Othmen, A.; Chatra, M.; Behm, D.G. Unilateral static and dynamic hamstrings stretching increases contralateral hip flexion range of motion. Clin. Physiol. Funct. Imaging 2015, 37, 23-29. [CrossRef]

8. Behm, D.G.; Cavanaugh, T.; Quigley, P.; Reid, J.C.; Nardi, P.S.M.; Marchetti, P.H. Acute bouts of upper and lower body static and dynamic stretching increase non-local joint range of motion. Graefe's Arch. Clin. Exp. Ophthalmol. 2016, 116, 241-249. [CrossRef]

9. Wilke, J.; Niederer, D.; Vogt, L.; Banzer, W. Remote effects of lower limb stretching: Preliminary evidence for myofascial connectivity? J. Sports Sci. 2016, 34, 1-4. [CrossRef]

10. Cruz-Montecinos, C.; González Blanche, A.; López Sánchez, D.; Cerda, M.; Sanzana-Cuche, R.; Cuesta-Vargas, A. In vivo relationship between pelvis motion and deep fascia displacement of the medial gastrocnemius: Anatomical and functional implications. J. Anat. 2015, 227, 665-672. [CrossRef]

11. Andrade, R.J; Freitas, S.R.; Vaz, J.R.; Bruno, P.M.; Pezarat-Correia, P. Provocative mechanical tests of the peripheral nervous system affect the joint torque-angle during passive knee motion. Scand. J. Med. Sci. Sports 2014, 25, 338-345. [CrossRef] [PubMed]

12. Pavan, P.G.; Stecco, A.; Stern, R.; Stecco, C. Painful Connections: Densification Versus Fibrosis of Fascia. Curr. Pain Headache Rep. 2014, 18, 1-8. [CrossRef] [PubMed]

13. Cowman, M.K.; Schmidt, T.A.; Raghavan, P.; Stecco, A. Viscoelastic Properties of Hyaluronan in Physiological Conditions. F1000Research 2015, 4, 622. [CrossRef] [PubMed]

14. Fede, C.; Angelini, A.; Stern, R.; Macchi, V.; Porzionato, A.; Ruggieri, P.; De Caro, R.; Stecco, C. Quantification of hyaluronan in human fasciae: Variations with function and anatomical site. J. Anat. 2018, 233, 552-556. [CrossRef] [PubMed]

15. Stecco, C.; Hammer, W.; Vleeming, A.; De Caro, R. Functional Atlas of the Human Fascial System; Elsevier Health Sciences: London, $\mathrm{UK}, 2015$.

16. Yucesoy, C.A.; Baan, G.C.; Huijing, P.A. Substantial inter-antagonistic epimuscular myofascial force transmission occurs in the rat between the deep flexor muscles and the muscles of the anterior crural and peroneal compartments. J. Electromyogr. Kinesiol. 2010, 20, 118-126. [CrossRef] [PubMed]

17. Stecco, C.; Stern, R.; Porzionato, A.; Macchi, V.; Masiero, S.; Stecco, A.; De Caro, R. Hyaluronan within fascia in the etiology of myofascial pain. Surg. Radiol. Anat. 2011, 33, 891-896. [CrossRef]

18. Krause, F.; Wilke, J.; Vogt, L.; Banzer, W. Intermuscular force transmission along myofascial chains: A systematic review. J. Anat. 2016, 228, 910-918. [CrossRef]

19. Huijing, P.A. Muscle as a collagen fiber reinforced composite material: Force transmission in muscle and whole limbs. J. Biomech. 1999, 32, 329-345. [CrossRef] 
20. Huijing, P.A. Muscular force transmission: A unified, dual or multiple sytem? A review and some explorative experimental results. Arch. Physiol. Biochem. 1999, 170, 292-311.

21. Huijing, P.; Baan, G. Myofascial Force Transmission Causes Interaction between Adjacent Muscles and Connective Tissue: Effects of Blunt Dissection and Compartmental Fasciotomy on Length Force Characteristics of Rat Extensor Digitorum Longus Muscle. Arch. Physiol. Biochem. 2001, 109, 97-109. [CrossRef]

22. Maas, H.; Meijer, H.J.M.; Huijing, P.A. Intermuscular Interaction between Synergists in Rat Originates from both Intermuscular and Extramuscular Myofascial Force Transmission. Cells Tissues Organs 2005, 181, 38-50. [CrossRef] [PubMed]

23. Yucesoy, C.A.; Koopman, H.J.F.M.; Baan, G.C.; Grootenboer, H.J.; Huijing, P.A. Extramuscular myofascial force transmis-sion: Experiments and finite element modeling. Arch. Physiol. Biochem. 2003, 111, 377-388. [CrossRef] [PubMed]

24. Yucesoy, C.A.; Baan, G.C.; Koopman, B.H.F.J.M.; Grootenboer, H.J.; Huijing, P.A. Pre-Strained Epimuscular Connections Cause Muscular Myofascial Force Transmission to Affect Properties of Synergistic EHL and EDL Muscles of the Rat. J. Biomech. Eng. 2005, 127, 819-828. [CrossRef] [PubMed]

25. Kaya, C.S.; Bilgili, F.; Akalan, N.E.; Temelli, Y.; Ates, F.; Yucesoy, C.A. Intraoperative experiments combined with gait analyses indicate that active state rather than passive dominates the spastic gracilis muscle's joint movement limiting effect in cerebral palsy. Clin. Biomech. 2019, 68, 151-157. [CrossRef] [PubMed]

26. Stecco, A.; Gilliar, W.; Hill, R.; Fullerton, B.; Stecco, C. The anatomical and functional relation between gluteus maximus and fascia lata. J. Bodyw. Mov. Ther. 2013, 17, 512-517.

27. Stecco, C.; Gagey, O.; Macchi, V.; Porzionato, A.; De Caro, R.; Aldegheri, R.; Delmas, V. Tendinous muscular insertions onto the deep fascia of the upper limb. First part: Anatomical study. Morphology 2007, 91, 29-37. [CrossRef]

28. Berthier, C.; Blaineau, S. Supramolecular organization of the subsarcolemmal cytoskeleton of adult skeletal muscle fibers. A review. Biol. Cell 1997, 89, 413-434. [CrossRef]

29. Nishimura, T.; Ojima, K.; Liu, A.; Hattori, A.; Takahashi, K. Structural changes in the intramuscular connective tissue during development of bovine semitendinosus muscle. Tissue Cell 1996, 28, 527-536. [CrossRef]

30. Passerieux, E.; Rossignol, R.; Letellier, T.; Delage, J.P. Physical continuity of the perimysium from myofibers to tendons: In-volvement in lateral force transmission in skeletal muscle. J. Struct. Biol. 2007, 159, 19-28. [CrossRef]

31. Street, S.F.; Ramsey, R.W. Sarcolemma: Transmitter of Active Tension in Frog Skeletal Muscle. Science 1965, 149, 1379-1380. [CrossRef]

32. Stecco, L. Il Dolore e le Sequenze Neuromiofasciali; IPSA Editore: Palermo, Italy, 1990.

33. Nordez, A.; Gross, R.; Andrade, R.; Le Sant, G.; Freitas, S.; Ellis, R.; McNair, P.J.; Hug, F. Non-Muscular Structures Can Limit the Maximal Joint Range of Motion during Stretching. Sports Med. 2017, 47, 1925-1929. [CrossRef] [PubMed]

34. Behm, D.G. The Science and Physiology of Flexibility and Stretching; Routledge: Abingdon, UK, 2018.

35. Korhonen Rami, K.; Saarakkala, S. Biomechanics and modeling of skeletal soft tissues. In Theoretical Bio-Mechanics; Klika, V., Ed.; IntechOpen: London, UK, 2011.

36. Pavan, P.G.; Stecco, C.; Darwish, S.; Natali, A.N.; De Caro, R. Investigation of the mechanical properties of the plantar apo-neurosis. Surg. Radiol. Anat. 2011, 33, 905-911. [CrossRef] [PubMed]

37. Stecco, C.; Pavan, P.; Pachera, P.; De Caro, R.; Natali, A. Investigation of the mechanical properties of the human crural fascia and their possible clinical implications. Surg. Radiol. Anat. 2013, 36, 25-32. [CrossRef] [PubMed]

38. Pavan, P.G.; Pachera, P.; Stecco, C.; Natali, A.N. Biomechanical behavior of human crural fascia in anterior and posterior regions of the lower limb. Med. Biol. Eng. Comput. 2015, 53, 951-959. [CrossRef]

39. Bilston, L.E.; Tan, K. Measurement of Passive Skeletal Muscle Mechanical Properties In Vivo: Recent Progress, Clinical Applications, and Remaining Challenges. Ann. Biomed. Eng. 2015, 43, 261-273. [CrossRef]

40. Meyers, S.A.; Seaber, A.V.; Glisson, R.R.; Nunley, J.A. Effect of hyaluronic acid/chondroitin sulfate on healing of full-thickness tendon lacerations in rabbits. J. Orthop. Res. 1989, 7, 683-689. [CrossRef]

41. Tamura, A.; Hongu, J.-I.; Matsumoto, T. Theoretical elastic tensile behavior of muscle fiber bundles in traumatic loading events. Clin. Biomech. 2019, 69, 184-190. [CrossRef]

42. Schleifenbaum, S.; Schmidt, M.; Möbius, R.; Wolfskämpf, T.; Schröder, C.; Grunert, R.; Hammer, N.; Prietzel, T. Load and failure behavior of human muscle samples in the context of proximal femur replacement. BMC Musculoskelet. Disord. 2016, 17, 149. [CrossRef]

43. Tamura, A.; Hayashi, S.; Matsumoto, T. Effect of Loading Rate on Viscoelastic Properties and Local Mechanical Heterogeneity of Freshly Isolated Muscle Fiber Bundles Subjected tTo Uniaxial Stretching. J. Mech. Med. Biol. 2016, 16, 1650086. [CrossRef]

44. Malanga, G.A.; Ibrahim, V. Regenerative Treatments in Sports and Orthopedic Medicine; Demosmedical: New York, NY, USA, 2018.

45. Morales-Orcajo, E.; Bayod, J.; Casas, E.B.D.L. Computational Foot Modeling: Scope and Applications. Arch. Comput. Methods Eng. 2015, 23, 389-416. [CrossRef]

46. Soderberg, G.L. Kinesiology: Application to Pathological Motion; Williams \& Wilkins: Baltimore, MD, USA, 1986.

47. Bennett, M.B.; Ker, R.F.; Imery, N.J.; Alexander, R.M. Mechanical properties of various mammalian tendons. J. Zool. 1986, 209, 537-548. [CrossRef]

48. Ker, R.F. Dynamic tensile properties of the plantaris tendon of sheep (Ovis aries). J. Exp. Biol. 1981, 93, 283-302. [PubMed]

49. Kubo, K.; Kanehisa, H.; Fukunaga, T. Effect of stretching training on the viscoelastic properties of human tendon structures in vivo. J. Appl. Physiol. 2002, 92, 595-601. [CrossRef] [PubMed] 
50. Duenwald, S.E.; Vanderby, R., Jr.; Lakes, R.S. Stress relaxation and recovery in tendon and ligament: Experiment and modeling. Biorheology 2010, 47, 1-14. [CrossRef] [PubMed]

51. Proske, U. Exercise, fatigue and proprioception: A retrospective. Exp. Brain Res. 2019, 237, 2447-2459. [CrossRef]

52. Smith, L.K.; Weiss, E.L.; Lehmkuhl, L.D. Brunnstrom's Clinical Kinesiology, 5th ed.; F.A. Davis: Philadelphia, PA, USA, 1996; pp. 138-142.

53. Kjaer, M. Role of Extracellular Matrix in Adaptation of Tendon and Skeletal Muscle to Mechanical Loading. Physiol. Rev. 2004, 84, 649-698. [CrossRef]

54. Dintenfass, L. Lubrication in Synovial Joints: A Theoretical Analysis. J. Bone Jt. Surg. Am. 1963, 45, 1241-1256. [CrossRef]

55. Chytil, M.; Strand, S.; Christensen, B.E.; Pekař, M. Calorimetric and light scattering study of interactions and macromolecular properties of native and hydrophobically modified hyaluronan. Carbohydr. Polym. 2010, 81, 855-863. [CrossRef]

56. Tadmor, R.; Chen, N.; Israelachvili, J.N. Thin film rheology and lubricity of hyaluronic acid solutions at a normal physiological concentration. J. Biomed. Mater. Res. 2002, 61, 514-523. [CrossRef]

57. Matteini, P.; Dei, L.; Carretti, E.; Volpi, N.; Goti, A.; Pini, R. Structural Behavior of Highly Concentrated Hyaluronan Biomacromolecules 2009, 10, 1516-1522. [CrossRef]

58. Tømmeraas, K.; Melander, C. Kinetics of Hyaluronan Hydrolysis in Acidic Solution at Various pH Values. Biomacromolecules 2008, 9, 1535-1540. [CrossRef] [PubMed]

59. Gatej, I.; Popa, M.; Rinaudo, M. Role of the $\mathrm{pH}$ on Hyaluronan Behavior in Aqueous Solution. Biomacromolecules 2005, 6, 61-67. [CrossRef] [PubMed]

60. Juel, C.; Klarskov, C.; Nielsen, J.J.; Krustrup, P.; Mohr, M.; Bangsbo, J. Effect of high-intensity intermittent training on lactate and $\mathrm{H}+$ release from human skeletal muscle. Am. J. Physiol. Endocrinol. Metab. 2004, 286, E245-E251. [CrossRef] [PubMed]

61. Karakuzu, A.; Pamuk, U.; Ozturk, C.; Acar, B.; Yucesoy, C.A. Magnetic resonance and diffusion tensor imaging analyses indicate heterogeneous strains along human medial gastrocnemius fascicles caused by submaximal plantar-flexion activity. J. Biomech. 2017, 57, 69-78. [CrossRef] [PubMed]

62. Perret, C.; Poiraudeau, S.; Fermanian, J.; Colau, M.M.L.; Benhamou, M.A.M.; Revel, M. Validity, reliability, and responsiveness of the fingertip-to-floor test. Arch. Phys. Med. Rehabil. 2001, 82, 1566-1570. [CrossRef] [PubMed]

63. Konrad, A.; Stafilidis, S.; Tilp, M. Effects of acute static, ballistic, and PNF stretching exercise on the muscle and tendon tissue properties. Scand. J. Med. Sci. Sports 2016, 27, 1070-1080. [CrossRef]

64. Roser, M.; Cameron, A.; Hannah, R. "Human Height". Available online: OurWorldInData.org (accessed on 7 October 2020).

65. Herda, T.J.; Cramer, J.T.; Ryan, E.D.; McHugh, M.P.; Stout, J. Acute Effects of Static versus Dynamic Stretching on Isometric Peak Torque, Electromyography, and Mechanomyography of the Biceps Femoris Muscle. J. Strength Cond. Res. 2008, 22, 809-817. [CrossRef]

66. Nordez, A.; McNair, P.; Casari, P.; Cornu, C. The effect of angular velocity and cycle on the dissipative properties of the knee during passive cyclic stretching: A matter of viscosity or solid friction. Clin. Biomech. 2009, 24, 77-81. [CrossRef]

67. Bishop, D.J. Warm up I: Potential mechanisms and the effects of passive warm up on exercise performance. Sports Med. 2003, 33, 439-454. [CrossRef]

68. Buchthal, F.; Kaiser, E.; Knappeis, G.G. Elasticity, Viscosity and Plasticity in the Cross Striated Muscle Fibre. Acta Physiol. Scand. 2008, 8, 16-37. [CrossRef]

69. Hill, A.V. The heat of shortening and the dynamic constants of muscle. Proc. R. Soc. Lond. Ser. B Biol. Sci. 2006, 126, 136-195. [CrossRef] 